\title{
Perbedaan Pola Pikir Orang Indonesia dan Orang Prancis melalui Karya Terjemahan
}

\author{
Sajarwa \\ Fakultas Ilmu Budaya, Universitas Gadjah Mada \\ sajarwa@ugm.ac.id
}

\begin{abstract}
Transfer of message in the translation process is always characterized by the difference of culture in the source language and the target language. Language, as a part of culture, affects the speaker mind including translator. Text of French literature (as source text, ST) and text of Indonesian literature (as target text, TT) could be an example of difference in mindset of French people as writer of French literature and Indonesian people as translator. The study results showed the differences in the mindset throught analyzes of (i) Active-Passive Construction of French pronoun on and passive di-, (ii) dominantly pronoun as means of topics continuity in French and repetition in Indonesian, and (iii) the difference of informational arrangement looked in impersonal construction of French with pattern of IL + IB and IB + IL in Indonesian.
\end{abstract}

Keywords : culture, mindset, translation, active-passive, topics continuity, information.

\section{PENDAHULUAN}

Ketika seseorang menerjemahkan suatu teks, dia tidak hanya mengalihkan pesan tetapi juga budaya. Proses pengalihan pesan teks bahasa sumber dipengaruhi oleh budaya penerjemah. Hal ini tercermin dari cara dia dalam memahami, memandang, dan mengungkapkan pesan itu melalui bahasa yang digunakan. Pengalihan pesan dalam proses penerjemahan selalu ditandai oleh perbedaan budaya bahasa sumber dan bahasa sasaran (Hoed, 2006). Konsep bahwa bahasa adalah budaya, dan budaya diwujudkan melalui perilaku kebahasaan, berlaku pada bidang penerjemahan. Hal ini dikarenakan penerjemahan juga merupakan tindak komunikasi interlingual, yang perwujudannya sangat dipengaruhi oleh budaya pengguna bahasa. House (2002:92), berpendapat bahwa seseorang tidak menerjemahkan bahasa tetapi budaya, sehingga dalam penerjemahan kita mengalihkan budaya bukan bahasa. Bahasa adalah media manusia berpikir secara abstrak di mana objek-objek faktual ditransformasikan menjadi simbol-simbol bahasa yang abstrak. Dengan adanya transformasi ini maka manusia dapat berpikir mengenai sebuah objek, meskipun objek itu tidak terinderakan saat proses berpikir itu dilakukan olehnya (Suriasumantri, 1998).

Sapir (1931) dan Whorf (1956) melihat bahwa pikiran manusia ditentukan oleh sistem klasifikasi dari bahasa tertentu yang digunakan manusia. Bahasa, sebagai bagian dari budaya, mempengaruhi pikiran penutur bahasa termasuk penerjemah. Pengaruh bahasa terhadap pikiran misalnya aspek bahasa yang mempengaruhi penalaran ruang bidang (reasoning spatial) dan aspek bahasa yang mempengaruhi penalaran terhadap pikiran lain (reasoning about other minds) (Slobin, 2003). Hal ini terjadi melalui habituasi dan melalui aspek formal bahasa, misalnya tatabahasa dan leksikon. Teks sastra (sebagai teks sumber) dan teks terjemahan (sebagai teks sasaran) dapat menjadi contoh pengaruh pola pikir dari bahasa sumber bagi penulis teks sastra dan bahasa sasaran bagi seorang penerjemah. Penerjemah karya sastra dituntut memiliki kemampuan sastra dan kepekaan budaya (Sastriani, 2007: 74) Perbedaan penalaran atau pola pikir dalam Tsu dan Tsa akan diungkap melalui analisis (i) Konstruksi Aktif-Pasif dalam bahasa Prancis dan bahasa 
Indonesia, (ii) Penataan Informasi dalam Wacana Bahasa Prancis dan Bahasa Indonesia, dan (iii) Kesinambungan Topik Wacana Bahasa Prancis dan Bahasa Indonesia. Penelitian ini menggunakan data dari tiga novel bahasa Prancis dan tiga novel terjemahan dalam bahasa Indonesia. Ketiga novel bahasa Prancis itu adalah (1) Vendredi ou la Vie Sauvage karya Michel Tournier diterbitkan oleh Gallimard tahun 1971 dan Kehidupan Liar diterjemahkan oleh Ida Sundari Husen diterbitkan Pustaka Jaya tahun 1992, (2) Madame Bovary karya Gustave Flaubert diterbitkan oleh Gallimard tahun 1972 dan Nyonya Bovary diterjemahkan oleh Winarsih Arifin diterbitkan oleh PT Dunia Pustaka Jaya tahun 1990, serta (3) Le Rocher de Tanios karya Amin Maalout diterbitkan oleh Grasser \& Fasquelle tahun 1993 dan Cadas Tanios diterjemahkan oleh Ida Sundari Husen diterbitkan oleh Yayasan Obor Indonesia tahun 1999. Penelitian ini adalah penelitian kualitatif dengan perspektif kajian bahasa dan budaya.

\section{KONSTRUKSI AKTIF-PASIF DALAM BAHASA PRANCIS DAN BAHASA INDONESIA}

Bahasa Prancis memiliki konstruksi pasif, auxiliaire + partisipe passé. Sebagai contoh ce stylo est acheté par mon père 'Pulpen itu dibeli oleh ayah' yang menempatkan nomina tak bernyawa ce stylo 'pulpen itu 'sebagai pasien. Bahasa Prancis menghindari bentuk pasif dengan konstruksi seperti itu yang menempatkan pasien nomina bernyawa. Dalam sejarah bahasa Prancis, konstruksi pasif seperti itu pernah menempatkan pasien nomina bernyawa. Kontruksi tersebut ditemukan pada novel Gargantua yang ditulis oleh François Rabelais. Novel itu diterbitkan tahun 1553, yaitu seseorang bernama Bacchus pada contoh Bacchus fut engendré par la cuisse de Jupiter 'Bacchus diturunkan dengan paha Jupiter' (hal. 45). Seperti yang dikemukakan oleh Rickard (2011: 75) bahwa mulai abad ke-15 konstruksi pasif yang menempatkan pasien nomina bernyawa mulai dibatasi dan diganti dengan bentuk pronominal. Mengapa penutur Prancis menghindari bentuk pasif dengan nomina bernyawa sebagai agen? Pada saat pemakaian bentuk pasif, ada pihak yang dijadikan inferior (lebih rendah) yaitu pasiennya. Oleh karena itu, ketika digunakan bentuk pasif, sebenarnya penutur secara tidak langsung memfokuskan inferioritas pada nomina yang menjadi pasien. Kalimat pasif di atas menginferiorkan pasiennya, yaitu «Bacchus » yang merupakan nomina manusia. Konstituen «Bacchus» menjadi pasien tindakan yang dilakukan oleh konstituen « la cuisse de Jupiter 'paha Jupiter ». Bentuk seperti ini cenderung dihindari dalam bP. Menghindari menginferiorkan pihak tertentu menjadi salah satu alasan mengapa penutur Prancis tidak menyukai bentuk pasif ini. Sikap ini berkaitan dengan sejarah panjang masyarakat Prancis. Dengan robohnya monarki dan terbentuknya republik, muncullah filosofi liberté, égalité, fraternité (kebebasan, kesetaraan dan persaudaraan). (Carpentier dan Lebrun, 2011: 24). Kesetaraan menjadi nilai yang mendasar bagi masyarakat Prancis. Sejak saat itu, hak-hak istimewa yang menjadikan satu pihak lebih superior dari pihak lain dihapus. Masyarakat menerima sistem Republik yang berlandaskan demokrasi dan kesetaraan, karena sistem pemerintahan monarki di mana satu pihak yang dijadikan penguasa tertinggi gagal. Latar belakang sejarah Prancis yang menyebabkan munculnya semboyan tersebut turut mempengaruhi budaya dan cara berpikir rakyatnya. Budaya dan cara berpikir tersebut kemudian mempengaruhi cara penutur Prancis menggunakan bahasanya.

Pada abad ke-17 terjadi pergolakan sosial, yakni munculnya kaum borjuis sebagai kelompok masyarakat baru. Kelompok kaum borjuis ini muncul akibat dari pengaruh revolusi 
industri. Sebelumnya, hanya ada dua kelompok masyarakat yaitu kelompok istana/bangsawan dan petani. Kelompok borjuis ini berada di antara kelompok istana/bangsawan dan petani. Mereka lebih terdidik dan menguasai perindustrian serta perdagangan (Carpentier dan Lebrun, 2011: 197). Pada masa ini muncul pronomina on. Pronomina on dipakai dalam komunikasi lisan, yang menunjukkan adanya kedekatan dan kesetaraan antar peserta wicara. Oleh karena itu, pronomina on dinamakan pronom de communication. Sikap para bangsawan yang tidak menerima kelompok borjuis sebagai kelompok masyarakat baru dan menempatkan mereka sederajat dengan petani membuat kelompok borjuis marah. Mereka menginginkan kesamaan dalam hukum dan diperbolehkan menduduki fungsi-fungsi pemerintahaan dan militer. Selain itu, mereka juga menuntut penghapusan hak-hak tuan tanah yang merugikan petani (Furet dan Richet, 1989: 78). Tuntutan kesetaraan inilah yang mendorong masyarakat Prancis, khususnya kelompok borjuis dan petani, menggunakan pronomina on dengan bentuk aktif tetapi bermakna pasif. Konstruksi kalimat dengan pronomina on bermakna pasif ini pelaku "dilemahkan" atau dilesapkan dan lebih menonjolkan tindakan. Demikianlah, mulai abad ke-17 pronomina on dipergunakan untuk menyatakan makna pasif (Gjesdal, 2008).

(1) On versa du vin de champagne à la glace. Emma frissonna de toute sa peau en sentant ce froid dans sa bouche. (MB, 82)

'Anggur champagne dihidangkan dengan es. Emma menggigil sekujur badannya ketika merasa dingin minuman itu dalam mulutnya. (NB, 65)'

(2) C'est là que l'on fait les pires fromages de culture y est coûteuse, parce qu'il faut beaucoup de fumier pour engraisser ces terres friables pleines de sable et de cailloux (MB, 108)

'Di sinilah dibuat keju Neufchatel yang paling tidak enak dari seluruh arondisemen. Bercocok tanam pun besar biayanya karena banyaknya pupuk yang diperlukan untuk merabuki tanahnya yang gampang remuk penuh pasir dan batu kerikil itu. (MB, 86)

Sapir dan Whorf menyatakan bahwa tiap-tiap budaya akan menafsirkan dunia dengan cara yang berbeda-beda dan perbedaan ini terkodekan dalam bahasa. Artinya, persepsi penutur terhadap dunia tercermin dalam bahasanya karena para penutur bahasa harus menjelaskan cara mereka memandang dunia. Bahasa dapat dikatakan sebagai kerangka dari pemikiran kita dan orang akan sulit untuk bisa berpikir di luar kerangka itu (Thomas dan Wareing, 2007: 37). Kebiasaan penutur Prancis menghindari penggunaan bentuk pasif pun terjadi secara tidak sadar. Sebab, penggunaan bahasa merupakan hasil dari modes pikiran penutur yang terendam jauh di bawah-sadar (Dardjowidjodjo, 2003: 140). Modes pikiran ini terbentuk dari budaya dan nilainilai yang diajarkan kepada penutur sejak kecil.

Berbeda dengan Prancis, bentuk pasif dalam bahasa Indonesia mempunyai kedudukan yang cukup signifikan. Indonesia memiliki kurang lebih 600 bahasa daerah. Bahasa daerah yang paling banyak digunakan di Indonesia adalah bahasa Jawa yaitu sekitar 50 juta penutur, sedangkan bahasa daerah lainnya hanya sekitar ratusan ribu penutur ${ }^{1}$. Prinsip dasar dalam budaya Jawa yaitu keseimbangan yang bertumpu pada kerukunan ${ }^{2}$.Prinsip tersebut tercermin dari bahasa Jawa yang

\footnotetext{
${ }^{1}$ Rahmadsyah Rangkuti, 2004, Language maintenance \& language shift: Linguistic consequences in multilingual setting dalam Julisa halaman 129.

${ }^{2}$ Asim Gunarwan, 2008, Rasa Kejawaan dan Pengungkapan Tindak Tutur Pengancam Muka di Kalangan Orang Jawa dalam Kelana Bahana Sang Bahasawan halaman 431.
} 
mengutamakan keharmonisan. Bahasa daerah sering berpengaruh pada bI dan karena sebagian besar penutur bI juga penutur bahasa Jawa, maka pengaruh antara keduanya juga besar ${ }^{3}$

Pemakaian bentuk pasif dalam bI merupakan salah satu strategi untuk menyampaikan pesan secara lebih sopan. Sebab, saat menggunakan bentuk pasif, keadaan dari peristiwa yang merupakan hasil dari perbuatan seseorang lah yang diutamakan. Sehingga, tidak ada pihak yang terasa memerintah atau pun diperintah (Dardjowidjojo, 2003: 137). Hal tersebut selaras dengan sifat bI yang mengutamakan keharmonisan. Contohnya:

(3) Apakah kamu sudah membeli bunganya?

(4) Apakah bunganya sudah dibeli?

Unsur memerintah lebih terasa pada kalimat (3) daripada (4) karena pelaku yang diharapkan atau diberi tanggung jawab yaitu 'kamu' secara langsung disebutkan, sedangkan pada kalimat (4) tidak dipentingkan siapa pelakunya, yang dipedulikan hanyalah keadaan peristiwanya. Pada percakapan sehari-hari, bentuk pasif dalam memberikan perintah atau bertanya seperti kalimat (4) lebih banyak ditemukan. Oleh karena keharmonisan dan kesopanan sangat diutamakan, penutur bI juga menjadi terbiasa dengan pola seperti itu.

Pemakaian pasif dalam bahasa lain seperti Inggris dan Prancis cenderung dianggap penyimpangan norma tapi pemakaian pasif dalam bI bukanlah penyimpangan, tapi justru normanya itu sendiri (Dardjowidjodjo, 2003:138). Perbedaan latar belakang sejarah, perkembangan masyarakat, dan budaya antara Prancis dan Indonesia menghasilkan karakter berbahasa yang berbeda. Ketiga faktor tersebut membentuk modes pikiran penutur yang tertancap dalam jiwa penutur secara tidak sadar. Sehingga tanpa disadari, sebenarnya konsep bahasa yang digunakan sehari-hari dapat mencerminkan budaya dan pengaruh budaya tersebut pada pola pikir penutur.

\section{KESINAMBUNGAN TOPIK WACANA}

Pada bagian ini akan diuraikan mengenai penerjemahan kesinambungan topik wacana bahasa Prancis ke dalam bahasa Indonesia. Analisis terjemahan ini untuk melihat pola pikir melalui penggunaan alat kesinambungan topik dalam teks bahasa Prancis serta teks terjemahan dalam bahasa Indonesia.

Topik memiliki kedudukan sentral dalam wacana. Oleh karena itu, topik selalu diacu dan dipertahankan oleh unsur-unsur sesudahnya sehingga menimbulkan kesinambungan topik. Wacana tersusun dari tuturan-tuturan yang berupa kalimat-kalimat yang saling berkaitan dan berhubungan dengan faktor luar bahasa atau fakta-fakta di luar bahasa sehingga kalimat-kalimat dalam wacana itu membentuk satu kesatuan yang bersifat komunikatif. Sifat komunikatif itu mengimplikasikan bahwa wacana harus mudah dipahami. Hal ini dapat terwujud jika dalam wacana ada keserasian dan keterpaduan makna di antara kalimat-kalimat pembentuknya. Kepaduan dalam wacana bersifat sistematis. Artinya, sebuah kesatuan yang tidak hanya dipandang dari bentuknya melainkan juga dari segi maknanya atau bersifat kohesif. Untuk menciptakan kepaduan itu diperlukan alat, yaitu alat kohesi (cohesion device). Alat kohesi itu

\footnotetext{
${ }^{3}$ Supriyadi, 1988, Pengaruh Akhiran E dalam Bahasa Jawa Terhadap bentuk -Nya dalam Bahasa Indonesia dalam Bahasa, Sastra dan Budaya Jawa halaman 30.
} 
dipergunakan untuk menghubungkan bagian satu dengan lainnya dalam wacana, sehingga hubungan antar bagian dalam wacana tersebut mengarah topik wacana.

Bahasa Prancis memiliki delapan alat kesinambungan topik, yaitu pronomina, substitusi, zero, pengulangan, ekuivalensi leksikal, penunjukan dengan artikel demonstratif, sinonimi, dan hiponimi. Berikut diuraikan penggunaan alat-alat kesinambungan topik tersebut. Pronomina ada berbagai jenis sebagai berikut. (i) Pronomina persona subjek akan dipakai untuk menggantikan topik wacana yang juga sebagai subjek; Pronomina persona subjek ini memiliki kebertahanan tinggi. Sekalipun diselai oleh topik lain yang beda jenis atau ada pihak lain yang meskipun sama jenis tetapi tidak berkedudukan sebagai topik, maka pronomina persona subjek sebagai alat kesinambungan topik tetap akan dipertahankan. (ii) Pronomina demonstratif akan dipergunakan bila ada unsur atau orang lain selain topik yang memiliki kesamaan jenis atau jumlah, (iii) Pronomina On akan digunakan bila pencerita ingin mengedepankan peristiwanya dan melemahkan pelaku. Substitusi akan dipergunakan bila topik wacana yang akan disubstitusi tersebut memiliki ciri khusus yang tidak bisa digantikan dengan pronomina. Pengulangan akan dipergunakan (i) bila penutur ingin adanya penekanan, (ii) bila ada dua nama yang keduanya sebagai topik, (ii) bila penutur ingin mengembalikan topik awal setelah adanya penyelaan topik lain, atau (iv) bila penggunaan pronomina persona subjek yang sudah terlalu panjang.

Berdasarkan frekuensi penggunaan alat kesinambungan topik wacana bahasa Prancis dan penerjemahannya dalam bahasa Indonesia memperlihatkan bahwa dalam bahasa Prancis pronomina dominan sebagai alat kesinambungan topik. Dominasi penggunaan pronomina ini dikarenakan bahasa Prancis memiliki berbagai jenis pronomina yang dipilah berdasarkan jenisnya yaitu, feminin-maskulin, tunggal-jamak, subjek-objek/langsung-tak langsung, dekatjauh, posesif. Dengan banyaknya jenis pronomina tersebut, orang Prancis lebih sering menggunakan pronomina bila dibandingkan dengan alat yang lain, misalnya pengulangan, zero, penunjukan, dll. Bahkan dengan adanya pembedaan jenis feminin-maskulin pronomina, bahasa Prancis memanfaatkan pronomina tersebut sebagai alat kesinambungan topik wacana sejauh 17 kalimat dan kalimat ke 18 baru menggunakan bentuk pengulangan. Dengan demikian, dapat dinyatakan bahwa untuk menciptakan kesinambungan topik wacana, bahasa Prancis cenderung menggunakan strategi pronominal.

Sementara itu, berdasarkan pada data dapat dikemukakan bahwa dalam wacana bahasa Indonesia pengulangan dominan sebagai alat kesinambungan topik. Bahasa Indonesia memiliki sembilan jenis alat kesinambungan topik, yaitu pronomina, substitusi, zero, pengulangan, ekuivalensi leksikal, penunjukan, pasif, sinonimi, dan hiponimi. Analisis terjemahan memperlihatkan bahwa pengulangan lebih banyak menggantikan pronomina. Artinya, pengulangan dalam teks bahasa Indonesia dipakai untuk menggantikan pronomina dalam teks bahasa Prancis. Hal ini disebabkan bahwa dalam bahasa Indonesia tidak mengenal jenis kelamin untuk pronomina ataupun nomina non insani. Pada contoh di bawah alat kesinambungan topik yang digunakan dalm bahasa Prancis adalah pronomina il 'dia' untuk menggantikan le navire 'kapal itu' sedangkan pada kalimat terjemahan bahasa Indonesia digunakan pengulangan karena dalam bahasa Indonesia tidak lazim pronomina menggantikan nomina non insani.

a. D'ailleurs à quoi bon? Le navire se dirigeait droit sur l'île.

b. Bientôt il allait jeter l'ancre à proximité de la plage, et une chaloupe allait s'en détacher....(VVS: 26) 
a. Lagi pula apalah gunanya? Kapal itu toh sedang menuju pulaunya.

b. Tak lama kemudian kapal itu tentu akan membuang sauhnya di dekat pantai, dan sebuah sekoci akan diturunkan. (KL: 26).

Setelah pengulangan, alat kesinambungan topik wacana bahasa Indonesia adalah pronomina. Pronomina dipakai sejauh 8 kalimat dan kalimat kesembilan menggunakan alat kesinambungan topik pengulangan. Dengan demikian, dapat dikemukakan bahwa bahasa Indonesia cenderung menggunakan strategi pengulangan sebagai alat kesinambungan topik wacana.

TABEL 1. Tabel Jenis Alat Kesinambungan Topik Wacana Bahasa Prancis dan Penerjemahannya dalam bahasa Indonesia

\begin{tabular}{|l|l|l|l|l|l|}
\hline \multicolumn{2}{|c|}{ Pola Kesinambungan Topik wacana Bahasa } \\
Prancis
\end{tabular}




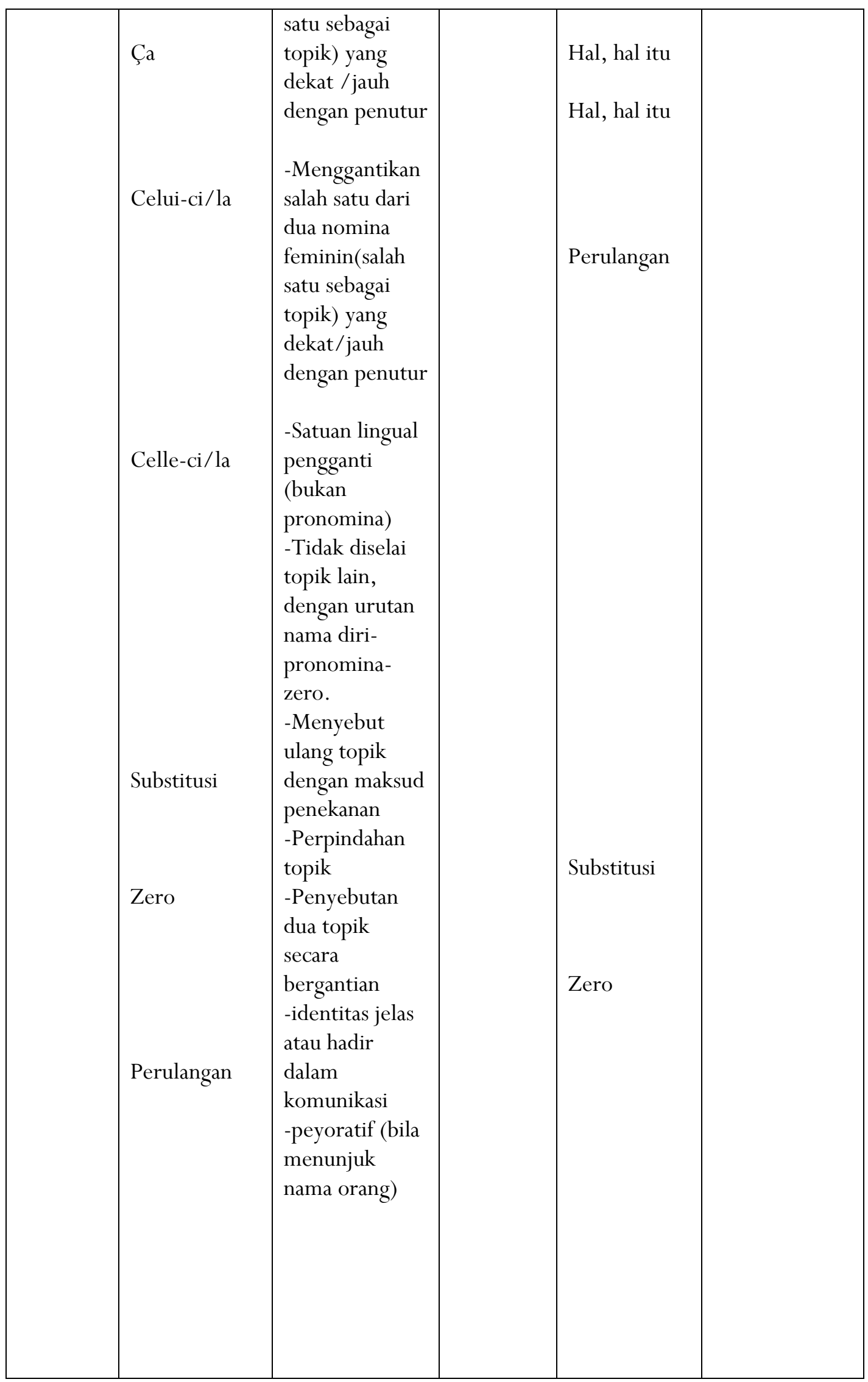




\begin{tabular}{|l|l|l|l|l|}
\hline $\begin{array}{l}\text { Penunjukan } \\
\text { dengan artikel } \\
\text { demonstratif } \\
\text { Ekuivalensi } \\
\text { leksikal } \\
\text { Sinonimi }\end{array}$ & & & & \\
Homonimi & & & & \\
Hiponimi & & & & \\
\hline
\end{tabular}

Berdasarkan pada skala prioritas penggunaan alat kesinambungan topik wacana bahasa Prancis dan bahasa Indonesia dapat dinyatakan bahwa dalam bahasa Prancis secara berurutan adalah pronomina-zero-penunjukan-pengulangan-substitusi-ekuivalensi leksikal-sinonimihiponimi. Sementara itu, dalam bahasa Indonesia adalah pengulangan-pronomina-substitusiekuivalensi leksikal-penunjukan-zero-pasif-sinonimi-hiponimi. Seperti yang terlihat dalam tabel di bawah.

TABEL 2. Skala Prioritas Penggunaan Alat Kesinambungan Topik Wacana Bahasa Prancis dan Bahasa Indonesia

\begin{tabular}{|l|c|l|c|}
\hline \multicolumn{1}{|c|}{ Bahasa Prancis } & $\mathbf{\%}$ & \multicolumn{1}{c|}{ Bahasa Indonesia } & $\mathbf{\%}$ \\
\hline Pronomina & $50 \%$ & Pengulangan & $34 \%$ \\
Zero & $11 \%$ & Pronomina & $20 \%$ \\
Penunjukan & $10 \%$ & Substitusi & $13 \%$ \\
Pengulangan & $10 \%$ & Ekuivalensi leksikal & $10 \%$ \\
Substitusi & $5 \%$ & Penunjukan & $8 \%$ \\
Ekuivalensi leksikal & $5 \%$ & Zero & $5 \%$ \\
Sinonimi & $5 \%$ & Pasif & $4 \%$ \\
Hiponimi & $4 \%$ & Sinonimi & $3 \%$ \\
& & Hiponimi & $3 \%$ \\
\hline Jumlah & $100 \%$ & Jumlah & $100 \%$ \\
\hline
\end{tabular}

\section{PENATAAN INFORMASI KALIMAT BAHASA}

\section{Status Informasi Kalimat Tunggal Bahasa Prancis dan Bahasa Indonesia}

Status informasi pada kalimat tunggal terdiri dari informasi lama (IL) dan informasi baru (IB). Status informasi berkaitan dengan ketakrifan (definitness). Nomina yang berciri taktakrif (indefinite) merupakan satuan lingual yang mengandung informasi baru, sedangkan nomina yang berciri takrif (definite) merupakan satuan lingual yang mengandung informasi lama.

Halliday (1967: 200) mengemukakan bahwa terdapat kecenderungan universal bahwa informasi lama berada sebelum informasi baru. Kecenderungan tersebut tampak dalam struktur informasi kalimat bahasa Indonesia dan juga bahasa Prancis. Dalam kalimat berpredikat verba, konstituen sebelum verba cenderung mengandung informasi lama, sedangkan konstituen 
sesudah verba dapat mengandung informasi lama dan dapat pula mengandung informasi baru ${ }^{4}$. Kalimat di bawah verbanya adalah vais faire 'akan membuat' berstatus IB, dan konstituen sebelum verba itu adalah je 'saya' berstatus IL. Dalam kalimat tersebut, bahasa sumber (BSu) yang berupa bahasa Prancis mengedepankan pelaku dengan pola IL+IB. Oleh karena itu, pada bahasa sasaran (BSa) atau kalimat terjemahan bahasa Indonesia juga mengedepankan pelaku dengan pola yang sama yaitu IL+IB.

(6) Le vais faire du café. (RT: 38)

IL IB

'Saya akan membuat kopi.' (CT: 23)

IL IB

Sehubungan dengan ketakrifan, dalam bahasa Prancis, nomina takrif ada yang berpemarkah dan tidak berpemarkah. Berikut contoh-contoh status informasi kalimat tunggal Bahasa Prancis dan Bahasa Indonesia. Penanda informasi baru Bahasa Prancis ditandai oleh artikel indefini (Sajarwa, 2000:281). Penanda informasi lama Bahasa Prancis ada yang berpemarkah dan ada juga yang tidak berpemarkah. Contoh yang berpemarkah berupa artikel defini, ajektif posesif, dan ajektif demonstratif. Sedangkan yang tidak berpemarkah berupa nomina nama diri dan pronomina. Untuk informasi lama Bahasa Indonesia ditandai oleh nomina takrif antara lain nama benda tunggal, nama diri, pronomina persona, nomina diikuti pronomina persona, nomina diikuti pronomina demonstratif, nomina diikuti nama diri, nomina diikuti pembatas, dan artikel diikuti nomina. Sementara informasi baru Bahasa Indonesia ditandai dengan nomina tak takrif antara lain nomina yang berpemarkah seperti suatu dan numeralia diikuti kata satuan (classifier), dan nomina yang tidak berpemarkah tak takrif (Baryadi, 2002: 72-73).

(7) Le galion imaginaire était un sérieux avertissement. (VVS : 28)

IL IB

'Bahtera khayali itu merupakan peringatan keras.' (KL: 28)

IL

IB

Pola urutan status informasi pada teks sasaran (TSa) atau dengan kata lain terjemahannya, seharusnya sama dengan pola urutan status informasi pada teks sumber (TSu). Akan tetapi, perbedaan pola urutan status informasi antara TSa dan Tsu juga dapat terjadi, seperti pada contoh berikut ini.

(7) Une peur panique envahit brusquement Robinson. (VVS : 148)

IB

IL

'Robinson mendadak panik.' (KL: 141)

IL IB

(8) Il faisait un temps magnifique. (VVS : 79)

IL IB

Cuaca luar biasa bagus. (KL : 76)

IL IB

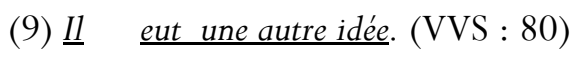

IL IB

'Muncul di kepalanya gagasan lain.' (KL : 77)

${ }^{4}$ I.Praptomo Baryadi, 2002, Dasar-dasar Analisis Wacana dalam Ilmu Bahasa, h. 75 
IL

IB

Pada kalimat-kalimat di atas, terdapat perbedaan pola urutan status informasi. Contoh kalimat (7) pola urutan status informasi pada TSa yaitu IL+IB, sedangkan pada TSu adalah IB-IL. Robinson pada TSu berstatus IL berada di akhir kalimat atau setelah IB. Akan tetapi pada TSa, Robinson yang juga berstatus IL berada di awal kalimat atau sebelum IB. Kalimat-kalimat sebelumnya pada TSu mengedepankan tentang suasana yang terjadi dalam wacana. Akan tetapi dalam TSa, pelakunya yang lebih dikedepankan, sehingga muncullah perbedaan pola urutan status informasi tersebut.

Pada contoh kalimat (8) pola urutan status informasi antara TSu dan TSa sama, tapi konstituen yang berstatus informasi lama berbeda. Informasi lama pada TSu adalah il faisait, sedangkan informasi lama pada TSa adalah cuaca, padahal un temps 'cuaca' pada TSu berstatus informasi baru dan berada setelah informasi lama. Perbedaan itu muncul karena kalimat pada TSu merupakan bentuk impersonnel, sedangkan pada TSa tidak ada bentuk impersonnel.

Konstituen yang menempati status informasi lama pada TSu dan TSa dalam kalimat (9) berbeda. Yang berstatus informasi lama pada Tsu adalah il, sedangkan IL pada Tsa adalah 'muncul di kepalanya'. Padahal il seharusnya diterjemahkan dia (laki-laki). Dilihat dari latar belakang wacana yang ada pada Tsu, yang lebih dikedepankan adalah pelakunya sehingga sering muncul penyebutan il di awal kalimat. Sementara pada Tsa lebih menonjolkan tentang suasana atau peristiwa yang dialami pelaku.

\section{URGENSI INFORMASI KALIMAT MAJEMUK BAHASA PRANCIS DAN BAHASA INDONESIA}

Dalam kalimat tunggal, konstituen yang mengandung informasi penting (IP) disebut tema (theme) dan kostituen yang mengandung informasi kurang penting (IKP) disebut rema (rheme). Tema dicirikan sebagai konstituen yang berada pada posisi paling kiri dari kalimat tunggal, sedangkan rema merupakan konstituen yang berada di sebelah kanan tema ${ }^{5}$. Berikut contoh kalimat yang memiliki struktur IP-IKP pada kalimat tunggal bahasa Prancis beserta terjemahannya dalam bahasa Indonesia.

(10) Le mur de pierre réverbérait la lumière comme un miroir. (VVS : 123)

IP IKP

'Tembok batu memantulkan cahaya bagaikan kaca.' (KL: 118)

IP

IKP

(11) Des yeux étrangers l'observent. (RT : 204)

IP IKP

'Sepasang mata asing mengawasinya.' (CT: 182)

IP IKP

Berdasarkan urgensi informasi yang dikandungnya, konstituen dalam kalimat tunggal dapat dipilah menjadi dua bagian yaitu konstituen yang mengandung informasi penting (IP) dan informasi kurang penting (IKP) ${ }^{6}$. Berbeda dengan status informasi lama dan informasi baru yang ditentukan berdasarkan ketakrifan, penentuan IP dan IKP dalam urgensi informasi berdasarkan

${ }^{5}$ I.Praptomo Baryadi, op.cit., h.89

${ }^{6}$ Ibid, h. 89 
letak konstituennya. Seperti yang telah dijelaskan sebelumnya, konstituen yang mengandung informasi penting berada di kiri, sedangkan konstituen yang mengandung informasi kurang penting berada di sebelah kanan. Dari contoh-contoh kalimat di atas, konstituen yang mengandung IP dan IKP pada TSu ketika diterjemahkan posisinya tetap sama. Akan tetapi, letak konstituen yang mengandung IP dan IKP antara BSu dan BSa juga dapat berbeda, seperti yang ditunjukkan oleh contoh kalimat berikut ini.

(7) Une peur panique envahit brusquement Robinson. (VVS : 148)

IP IKP

'Robinson mendadak panik.' (KL: 141)

IP IKP

(12) Le curé eut un moment d'espoir. (RT : 99)

IP IKP

'Sesaat muncul secercah harapan dalam hari pastor itu.' (CT: 81)

IP

IKP

Pada kalimat (7), yang berstatus informasi penting (IP) adalah une peur panique, sedangkan pada kalimat terjemahan yang berstatus IP adalah Robinson. Padahal Robinson di dalam kalimat BP berstatus sebagai informasi kurang penting (IKP). Perbedaan itu terjadi karena kalimat (7) mengedepankan keadaan 'kepanikan' yang kemudian diikuti oleh pengalam. Sebaliknya, kalimat terjemahan mengedepankan seseorang (pengalam) yang kemudian diikuti oleh keadaan. Hal yang sama juga terjadi pada kalimat (12). Pada kalimat (12) yang dikedepankan adalah pengalam yaitu le cure 'pastor itu', sedangkan pada kalimat bahasa Indonesia yang dikedepankan adalah keadaan 'sesaat muncul secercah harapan'.

\section{KESIMPULAN}

Analisis di penelitian ini memperlihatkan kontras antara penggunaan bentuk pasif dalam bP dan bI. Bentuk pasif bahasa Prancis dan bahasa Indonesia sangat terkait dengan kebudayaan masyarakat yang melatarinya. Bahasa Prancis menghindari bentuk pasif pasien nomina bernyawa. Hal ini dikarenakan adanya anggapan bahwa pasien tersebut diinferiorkan sesuatu yang bertentangan dengan slogan masyarakat Prancis yaitu égalité 'kesetaraan'. Untuk menghindari itu maka diciptakan bentuk kalimat aktif dengan pronomina on yang bermakna pasif. Sementara itu, penutur bahasa Indonesia menggunakan bentuk pasif di- untuk menjaga harmonisasi antar penutur. Dengan bentuk pasif di- antarpeserta tutur tidak ada kesan 'diperintah' seperti atasan bawahan tetapi hubungan keduanya setara.

Berkaitan dengan penggunaan alat kesinambungan topik wacana, hasil analisis di atas menunjukkan bahwa penggunaan pronomina sebagai alat kesinambungan topik wacana bahasa Prancis lebih dominan. Bahasa Prancis memiliki berbagai jenis pronomina. Dengan demikian, dapat dinyatakan bahwa untuk menciptakan kesinambungan topik wacana, bahasa Prancis cenderung menggunakan strategi pronominal.

Sementara itu, dalam wacana bahasa Indonesia penggunaan pengulangan sebagai alat kesinambungan topik lebih dominan. Pengulangan lebih banyak menggantikan pronomina. Dengan demikian, dapat dikemukakan bahwa bahasa Indonesia cenderung menggunakan strategi pengulangan sebagai alat kesinambungan topik wacana. 
Berkaitan dengan penataan informasi, terdapat perbedaan pola urutan konstituen berdasarkan status informasi maupun urgensi informasi, yaitu pada konstruksi impersonel. Pola urutan BP yaitu IL + IB sementara dalam terjemahan bahasa Indonesia IB + IL. Adapun perbedaan IP dan IKP terletak pada fokus. Bagian kalimat yang difokuskan mengandung IP.

\section{DAFTAR PUSTAKA}

Baryadi, Praptomo. 2000. "Konstruksi Perurutan Waktu pada Kalimat dalam Wacana Bahasa Indonesia". Disertasi. Universitas Gadjah Mada. Yogyakarta. . 2002. Dasar-dasar Analisis Wacana dalam Ilmu Bahasa. Pustaka Gondosuli.

Yogyakarta.

Carpentier, Jean dan Lebrun, François. 2011 . Sejarah Prancis, dari zaman prasejarah hingga akhir abad ke-20 . Jakarta : Kepustakaan Populer Gramedia

Dardjowidjojo, Soenjono. 2003. "Bentuk Pasif sebagai Cermin Pikiran Bangsa Indonesia" dalam Rampai Bahasa, Pendidikan, dan Budaya. Jakarta: Yayasan Obor. Hal 129-140.

Hoed, Benny H. 2006. Penerjemahan dan Kebudayaan. Jakarta: Pustaka Jaya.

House, J. 2002. "Universality versus Culture Specificity in Translation.” Dalam Alessandra Ricardi (ed.). Translation Studies: Perspective on an Emerging Discipline. Cambridge:CambridgeUniversityPress

Gunarwan, Asim. 2008. Rasa Kejawaan dan Pengungkapan Tindak Tutur Pengancam Muka di Kalangan Orang Jawa. Dalam Kelana Bahana Sang Bahasawan. Jakarta: Penerbit Universitas Atma Jaya

Sajarwa. 2000.”Status Informasi dalam Kalimat Bahasa Prancis” dalam Jurnal Humaniora. Vol. 12 No. 3 hal. 279-284.

Sapir, E. 1931. "Conceptual categories in Primitive Languages”. Science. Vol 74. Hal 578.

Sastriani, Siti Hariti. 2007. "Transformasi Gaya Bahasa dalam Sastra Terjemahan” dalam Humaniora. Vol 19 No. 1 hal 70-80

Slobin, I. 2003. "Language and Thought online: Cognitive consequences of Linguistic Relativity" dalam Language in Mind: Advances in the Study of Language and Thought. Gentner \& Goldin-Meadow (eds). Cambridge Press.

Suriasumantri, H. 1998. Ilmu dalam Perspektif. Jakarta: Yayasan Obor.

Thomas, Linda dan Wareing, Shan. 2007. Bahasa, Masyarakat dan Kekuasaan. Jakarta : Pustaka Pelajar.

Whorf, B L. 1956. Language, Thought, and Reality: Selested Writings of Benjamin Lee Whorf, ed. J B Caroll, MIT Press. 